\title{
PCR-based SNP Markers for Sex Identification in Date Palm (Phoenix dactylifera L.) cv. KL1
}

\author{
Kawee Sujipuli ${ }^{1}$, Suphattha Kaeomani ${ }^{2}$ and Narisa Kunpratum ${ }^{2, *}$ \\ ${ }^{I}$ Department of Agricultural Science, Faculty of Agriculture Natural Resources and Environment, \\ Naresuan University, Phitsanulok 65000, Thailand \\ ${ }^{2}$ Department of Biology, Faculty of Science, Naresuan University, Phitsanulok 65000, Thailand
}

('Corresponding author's e-mail: Narisak@nu.ac.th)

Received: 24 May 2020, Revised: 2 June 2021, Accepted: 4 June 2021

\begin{abstract}
The date palm (Phoenix dactylifera L.) is a valuable commercial plant in the Arecaceae family. It is a sweet, edible fruit containing a lot of nutrients including carbs, sugar, protein, and potassium. Maejo 36 or KL1 is a Thai date palm with excellent fresh fruit quality that is mostly grown in Thailand's northern and northeastern areas. The main issue with date palm farming is that there is no reliable way to discriminate between male and female seedlings prior to flowering, which takes 3 - 5 years after planting. An increase in the number of female date palm plants in commercial orchards may increase in date production and profitable investment. The present research aims to develop Single Nucleotide Polymorphisms (SNP) markers for the sex identification of date palm cv. KL1. The SNP markers were designed by analysis of nucleotide sequence difference from GenBank (accession number GL746268.1). The results revealed that SNP primers; PH02F - PdaNu01 (PdaNU02 or PdaNU03) - PdaNU05 used in multiplex PCR technique can precisely distinguish the sex of date palm by generating 2 different sizes of PCR-products in male plants, and only 1 size of PCR-product in female plants. This research indicates that SNP markers with multiplex-PCR technique are a high potential method for identifying the sex of date palm cv. KL1 may be used to increase female plants for cultivation at the seedling stage, which is highly beneficial for commercial date palm production.
\end{abstract}

Keywords: Date palm, Markers, PCR, Sex determination, Single Nucleotide Polymorphisms (SNP)

\section{Introduction}

Date palm (Phoenix dactylifera L.; $2 \mathrm{n}=36$ ) is an important economic fruit of the Middle East Arabian, Peninsula and North Africa. It can grow in very hot, dry, or semi-arid climates [1]. The date fruits contain various kinds of nutrition which are mainly carbohydrate (44 - 88), dietary fibre (6.4 - 11.5 $\%$ ), fat $(0.2-0.5 \%)$, protein $(2.3-5.6 \%)$, minerals and also vitamins [2-5]. Sweet date fruits provide a good source of energy and were reported to prevent cancer, heart disease, dyslipidemia and atherosclerosis [6,7]. In Thailand, the Thai-date-palm cultivar KL1 or Maejo36 has been developed from the cross of Deglet Nour and Barhi cultivars, widely cultivated in the Northern and North-Eastern regions. It can adapt to a humid climate, flower in 3 - 5 years, produce large fresh fruits and give a high yield per crop [8]. There are 2 main methods for date palm propagation. The most common method is the vegetative propagation of offshoots which ensures the sex and phenotype from the parent plant [1] but there are few offshoots produced from 1 parental date palm and also high risk to infectious disease from cutting the offshoots from parents [9]. The second propagation method is seed propagation providing a great number of seedlings from the sexual cross [10]. The limitation was that individual seedling withinpopulation exhibited high genotypic and phenotypic variation such as gene segregations, growths, fruit qualities and production, and sex types. About $50 \%$ of the seedlings are usually male $[1,11]$ which cannot produce fruit. The sex of date palm cannot be identified until date palm begins to flower after 5 to 10 years depending on cultivars [12]. Additionally, there is no report for the success of sex identification of date palm by distinguishing the morphology of seedlings and cytogenetics $[9,13]$. To ensure profitable cultivation of date palm, several efforts have established reliable approaches to distinguish its gender determination at an early seedling stage before its plantation. Molecular marker approaches based on the direct analysis of genomic DNA have been widely used for the study of sex determination in date palm 
seedlings. For example, random amplified polymorphic DNA (RAPD) marker (A10, A12, and D10) can identify sex types of date palm in Bertamoda, Malakabi, and Dajna cultivar [14], and microsatellite markers (P06) also enable to use for sex identification of Deglet Nour cultivar [1]. Based on the genetic information regulation sex-determining mechanism, the 2 sex forms of Phoenix species are genetically controlled by a pair of an XY chromosomal system (XX, female; and XY, male). Moreover, their nucleotide sequences of date palm, Khalas cultivar (accession number GL746268.1), have been published by Al-Dous et al. [15] which provided to understand its genetic information of the sex chromosome evolution, diversified from a common autosomal origin among the dioecious Phoenix species [16]. In comparison, many loci of single nucleotide polymorphisms (SNPs) have distributed through X and Y chromosomes) to segregate with gender [15]. The benefits of SNP assays include a lower error rate and the parallel assay of multiple SNP. For these reasons, the SNP loci are used for DNA markers for sex identification of Pistachio (Pistacia vera L.) [17] and papaya (Carica papaya L.) [18]. Hence, the goal of this study is to create SNP primers to determine the sex type of date palm cv. KL1. In the same response, male and female plants are anticipated to exhibit distinct PCR profiles. This SNP method should help commercial date palm farming save time and money.

\section{Materials and methods}

Plant materials and DNA extraction

Individual young leaf of Thai date palm (KL1 cultivar) was separately collected from 2 known sex genotypes (male and female), identified by inspection of flower morphology, from the farm in Fang district Chiang-Mai province of Thailand. All samples were stored at $-20{ }^{\circ} \mathrm{C}$ until further genomic DNA (gDNA) extraction, which was performed with at least 3 biological replicates of either a male or a female sample. A young leaf sample (approximately $50 \mathrm{mg}$ ) was ground to a fine powder in liquid nitrogen and stored at $-80^{\circ} \mathrm{C}$ until required for use. Total genomic DNA (gDNA) was extracted using the InnuPREP Plant DNA Kit (Analytik Jena, Germany) according to the manufacturer's instructions. In brief, the leaves of date palm $(50 \mathrm{mg})$ were ground into a fine powder with a mortar using liquid nitrogen. The frozen powdered tissue was transferred into a $2 \mathrm{~mL}$ microcentrifuge tube, subsequently treated with lysis solution $(400 \mu \mathrm{L})$, and mixed thoroughly by vortexing before incubating at $65{ }^{\circ} \mathrm{C}$ for $30 \mathrm{~min}$. The precipitation buffer $\mathrm{P}(100 \mu \mathrm{L})$ was added into the mixture, well mixed by vortexing, and incubated at room temperature for $5 \mathrm{~min}$. The solution was centrifuged at 13,200 rpm for $5 \mathrm{~min}$, and its supernatant was carefully filtered into a spin column placed on a receiver tube. This was centrifuged at 12,000 rpm for $1 \mathrm{~min}$, and the flow-through was collected and added with $10 \mathrm{mg} / \mathrm{L}$ RNase $(4 \mu \mathrm{L})$ before incubating at room temperature for $5 \mathrm{~min}$. After that, the binding solution SBS $(200 \mu \mathrm{L})$ was added to the mixture and mixed by pipetting. The sample was filtered into a spin column placed on a new receiver tube, then centrifuged for $2 \mathrm{~min}$ at $12,000 \mathrm{rpm}$. The sample was twice washed with washing solution MS $(650 \mu \mathrm{L})$ then centrifuged for $1 \mathrm{~min}$ at $12,000 \mathrm{rpm}$. The spin column was placed on an elution tube, and then the elution buffer $(200 \mu \mathrm{L})$ was added into the spin column followed by incubation at room temperature for a minute. The elution solution, containing gDNA, was collected by centrifuging at 8,000 rpm for a minute.

The gDNA purity was assessed by running them on $1.5 \%(\mathrm{w} / \mathrm{v})$ agarose gel dissolved in $1 \mathrm{X}$ TAE, visualized the PCR products by staining with $0.001 \%$ ethidium bromide (v/v) under UV light, and photographed using a gel document system (Vilber lourmat, E-BOX-1000/26Mi, USA).

\section{SNP primer design}

Al-Mahmoud et al. [19] have reported that 4 single nucleotide polymorphisms (SNPs) presented along with base sequences (accession number GL746268.1) at the position 4640-5280 in the male but not in the female of date palm, Khalas cultivar. The first-, second-, third-, and fourth-SNP loci (positions 4666, 4954, 4964-5 and 4960, respectively) were used to design the SNP-forward markers for diagnostic sex determination of date palm. At each SNP site, SNP-forward markers were designed by using the criteria that an SNP marker contained the $1^{\text {st }}$ original-nucleotide mismatch closest at the $3^{\prime}$ end of its markers, such as PH02-F, PdaNU01-F, PdaNU02-F and PdaNU03-F (Table 1). Additionally, all designed SNP-forward primers were hypothesized to amplify only a male-specific DNA template of date palm. Meanwhile, the base sequences at position 5261-5280 were used to commonly design a reverse primer (PdaNU05-R) (Table 1), which were hypothesized to amplify in both a male- and female-specific DNA template of date palm. 


\section{Sex determination using PCR technique with SNP primers}

The simple PCR technique with di-primers of individual SNP forward primer (either PH02-F, $P d a$ NU01-F, PdaNU02-F, or PdaNU03-F) and a reverse primer ( $P d a$ NU05-R) (Table 1) was validated sex determination of date palm. The PCR reaction $(20 \mu \mathrm{L})$ contained $1 \mu \mathrm{L}$ of DNA template $(50 \mathrm{ng} / \mu \mathrm{L}), 1$ $\mu \mathrm{L}$ of forward primer $(10 \mathrm{mM}), 1 \mu \mathrm{L}$ of reverse primer $(10 \mathrm{mM})$, sterilized distilled water $(7 \mu \mathrm{L})$, and OnePCR ${ }^{\mathrm{TM}}$ Plus (Biohelix, Taiwan) $(10 \mu \mathrm{L})$ (composed of Taq DNA polymerase, PCR buffer, dNTP, gel loading dyes and fluorescence dyes). This reaction was performed under the following conditions; predenaturation 1 cycle $\left(95{ }^{\circ} \mathrm{C}\right.$ for $5 \mathrm{~min}$ ), followed by amplification 30 cycles (denaturation at $95{ }^{\circ} \mathrm{C}$ for $30 \mathrm{~s}$, annealing at $55^{\circ} \mathrm{C}$ for $30 \mathrm{~s}$, and extension at $72{ }^{\circ} \mathrm{C}$ for $1 \mathrm{~min}$ ); and final extension 1 cycle $\left(72{ }^{\circ} \mathrm{C}\right.$ for $5 \mathrm{~min}$ ) in a T100TM thermal cycler (Bio-Rad, USA). The PCR product was kept at 4 or $-20{ }^{\circ} \mathrm{C}$ and was further separated on $1.5 \%(\mathrm{w} / \mathrm{v})$ agarose gel with $1 \mathrm{X}$ TAE buffer. The amplified PCR was visualized and photographed under ultraviolet light by the gel document system (Vilber lourmat, E-BOX-1000/26Mi, USA).

Meanwhile, multiplex PCR technique with tri-primers was subsequently used for sex identification of date palm. A set of primers consisted of 3 primers, which were PH02F, individual forward SNP primer (either $P d a$ NU01-F, $P d a$ NU02-F, or $P d a$ NU03-F) and a reverse primer (PdaNU05-R) (Table 1). The multiplex PCR technique was carried out in the same condition above.

Table 1 List of primers used for PCR amplification.

\begin{tabular}{ccccc}
\hline Primer Name & Direction & Base sequence (5'-3') & $\begin{array}{c}\text { Primer } \\
\text { location** }\end{array}$ & $\begin{array}{c}\text { Product size } \\
\text { (bp)**** }\end{array}$ \\
\hline PH02* & F & GGCAATAGCACCATAGTAAATTGCCTA & $4640-4666$ & 640 \\
$P d a \mathrm{NU} 01$ & $\mathrm{~F}$ & GCCATATATCAAGGTCCTATCTTTTG & $4929-4954$ & 352 \\
$P d a \mathrm{NU} 02$ & $\mathrm{~F}$ & CCTATCTTTTGGAGATCCGCA & $4945-4965$ & 337 \\
$P d a \mathrm{NU} 03$ & $\mathrm{~F}$ & CTTTTGGAGATCCGCACACCG & $4950-4960$ & 332 \\
$P d a \mathrm{NU} 05$ & $\mathrm{R}$ & CCGAGTCATCCAGACTAAGG & $5261-5280$ & - \\
\hline
\end{tabular}

Note * the PH02 was publicized by Intha et al. [8]; ** the primer location was designed from the date-palm sequence (accession number GL746268.1) reported by Al-Mahmoud et al. [19]; *** each PCR product was amplified by combing of individual forward (F) primer (either PH02, PdaNU01, PdaNU02, or PdaNU03) and reverse (R) primer (PdaNU05).

\section{Results and discussion}

Validating di-marker specificity based on the SPCR assay for date-palm sex determination

Four di-primer combinations of a 1-forward (F) primer (either PH02, PdaNU01, PdaNU02, or $P d a \mathrm{NU} 03)$ and a 1-reverse (R) primer (PdaNU05) were firstly validated for sex determination specificity of date palm, cultivar KL1, through a single PCR (sPCR) reaction. The result showed that the di-primer pair of PH02-F and PdaNU05-R enabled to amplify specifically of an expected PCR amplicon size, corresponding to $640 \mathrm{bp}$ in length in the DNA template of male samples (Figure 1A). Whereas, other 3 di-primer pairs (PdaNU01-F/PdaNU05-R, PdaNU02-F/PdaNU05-R, or PdaNU03-F/ PdaNU05-R) can generate the PCR amplicon in both expected-male and unexpected-female samples, corresponding to 352 (Figure 1B), 337 (Figure 1C), or 332 (Figure 1D) bp long respectively. Results indicated that of 4 diprimer pairs only the PH02-F/PdaNU05-R primer pair was successfully distinguished male and female among tested date-palm samples. This primer pair amplified the expected PCR product size (approximately $640 \mathrm{bp}$ ) in male samples, but absent the PCR product in female samples. 

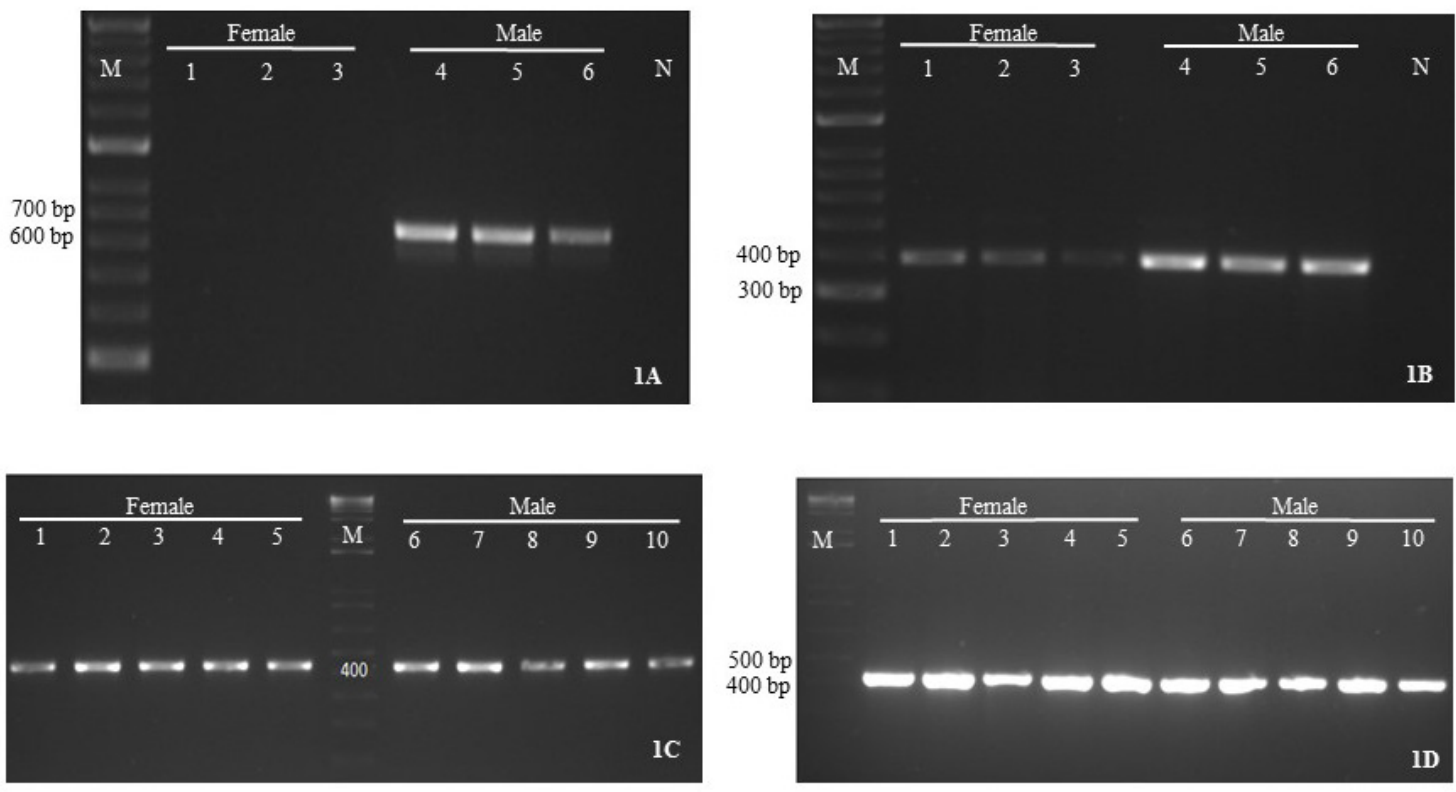

Figure 1 PCR-amplicon profiles of 2 sex types of date palm (KL1 cultivar) generated by an sPCR assay with 4 di-primer-combination.

Note: The PCR product amplified by using a primer pair of PH02-F/PdaNU05-R (A); PdaNU01F/PdaNU05-R (B); PdaNU02-F/PdaNU05-R (C) and PdaNU03-F/PdaNU05-R (D). M represents the DNA marker of the 100 bp DNA ladder RTU (GeneDireX, USA). Different lane number indicates different female or male samples.

\section{Development of tri-markers based on the multiplex PCR assay for date-palm sex determination}

As explained in the previous section, only the di-primer combination of $\mathrm{PH} 02-\mathrm{F} / \mathrm{PdaNU} 05-\mathrm{R}$ primer pair was able to distinguish male and female genotypes by considering present and absent PCR amplicon, respectively. This limitation was that the absence of the PCR product in the female genotype might be caused by no or low amount of DNA template. Therefore, the tri-primer combinations with multiplex PCR assay were developed to enhance the efficiency of date-palm sex determination. Three primers ( 2 forward primers and 1 reverse primer) in 1 reaction with multiplex PCR were applied for enhancing the possibility for generating the various sizes and number of PCR products by polymorphism between male and female samples. The results showed that 2 amplified PCR products were observed on the agarose gel from all male samples whereas only 1 amplified PCR was detected from all female samples (Figure 2). Of this, primer set 1: PH02F - PdaNU01 - PdaNU05 produced 2 bands with 350 bp and $640 \mathrm{bp}$ in size in male date palm and 1 band with $350 \mathrm{bp}$ in female date palm (Figure 2A). Primer set 2: PH02F - PdaNU02 - PdaNU05 generated 2 bands with $330 \mathrm{bp}$ and $640 \mathrm{bp}$ in size in male date palm and 1 band with 330 bp in female date palm (Figure 2B). Primer set 3: PH02F - PdaNU03 - PdaNU05 gave 2 bands with $330 \mathrm{bp}$ and $640 \mathrm{bp}$ in size in male date palm and 1 band with $330 \mathrm{bp}$ in female date palm (Figure 2C). These results indicated that there was polymorphism between male and female date palm cv. KL1. 


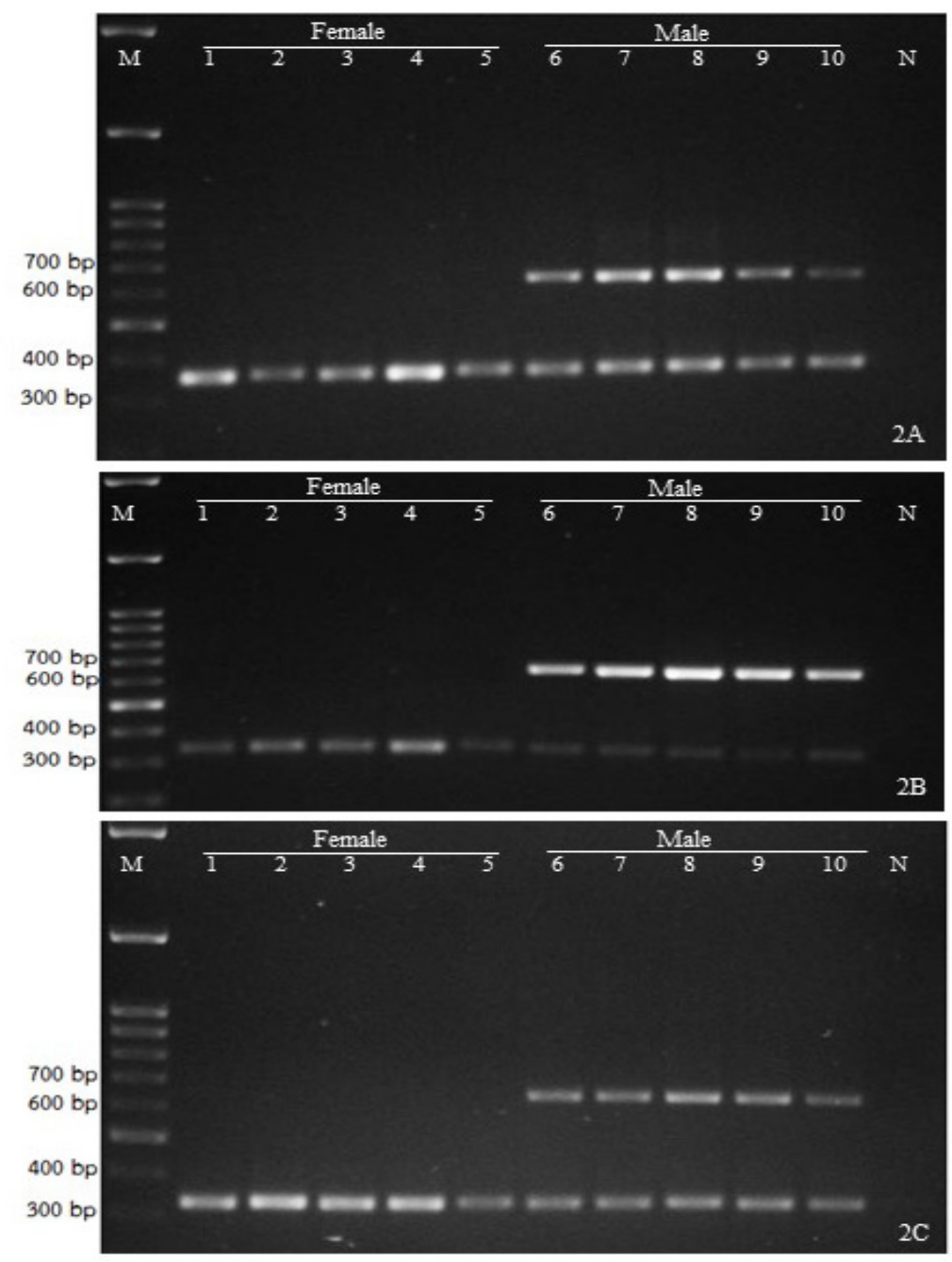

Figure 2 Analysis of PCR products obtained from set of tri-primers; PH02F-PdaNU01-PdaNU05 (A), PH02F- PdaNU02-PdaNU05 (B) and PH02F-PdaNU03-PdaNU05 (C) on $1.5 \%$ agarose gel. Legend: Lane $M$ was 100bp DNA Ladder H3 RTU (Ready-to-Use) (Genedirex, Taiwan). Lane 1 - 5 were female samples, numbers $1-5$, respectively. Lane 6 - 10 were male samples, numbers 1-5 respectively. Lane $\mathrm{N}$ was a negative control.

Molecular marker, as a new tool in screening, diagnosis, and genetic relationship analysis in plants [20], can be useful to apply for sex determination in various plants [21-24]. In the present study, the sex determination of date palm cv. KL1 was successful by using multiplex PCR and SNP primers developed based on single-base differences between DNA of different individuals [25]. According to the SNP primer design, forward primers (PdaNU01, PdaNU02 and PdaNU03) contained nucleotide at 3'end which was complementary to the SNP site of the male plant and enhanced the specificity of amplification in male date palm. However, they could bind to the DNA template of both expected male and unexpected females which generated the PCR amplicon in both samples. Reasons for this might be due to falsepositive amplification in females, caused by its nucleotide containing the chimeric sequence [26], and also due to less annealing specificity between primer and target-DNA [27, 28]. A similar study was conducted by Horn et al. [29], who reported that only the SNP PPR621.5 (of 10 tested-SNP markers) significantly associated with fertility restoration of the sunflower genome was a reproducible PCR amplicon. They successfully used this to develop a marker (detection of the $\mathrm{C}$ nucleotide at $173,473,513$ positions) for the identification of restorer and maintainer lines by amplifying the differentially amplified PCR size between both lines. Furthermore, 3 SNP markers (out of 7) designed at the sex-determining region were useful genetic markers for sex identification in yellowtail fish (Seriola quinqueradiata) in 
Japan [30]. Additionally, forward primers were able to match DNA template giving PCR products in both male and female date palms. It might be because the SNP primers designed based on the genetic information of date palm cv. Khalas containing different nucleotide sequences compared to cv. KL1. In the current research, only the $\mathrm{PH} 02$ forward primer can separate male and female plants constantly generating PCR products in male date palm because PH02 forward primer was designed from the SNP site which is very specified to male date palms [19]. Taking together, 2 new SNP primers with PH02 forward primers gave a different number of amplicons between male and female date palm. The present finding was similar to reports of Intha and Chaiprasart [8], they use PCR-based-tetra primers to identify the sex of date palm with 2 amplicons from the male plant and 1 amplicon from the female plant. The sequence of PCR products from female samples compared to the sequence of NCBI accession number GL747212.1 found that nucleotide sequences of all female samples of date palm cv. KL1 was similar to nucleotide sequences from NCBI database with aligned score 95.81-99.48\% (data not shown). The noticeable difference between the nucleotide sequence could have resulted from base-pair substitution causing the alteration of nucleotide. Furthermore, base deletion might have also contributed to the difference. Considering the nucleotide sequence of date palm cv. KL1, the aligned score was 93.46 $98.95 \%$ in female plants while the male had $87.57-97.64 \%$ which posits variation between the population of date palm cv. KL1.

\section{Conclusions}

In conclusion, sex identification in date palm (Phoenix dactylifera L.) cv. KL1 was effective using multiplex PCR-based SNP markers. Tri-primers (2 forward primers and 1 reverse primer) were used in the PCR process, which resulted in varied quantities and sizes of PCR product between male and female date palms. This method with SNP-specific markers is applicable in the sex determination of Thai date palm cv. KL1 at an early stage of development. Adoption of this technique will save the cost of cultivation and improve commercialization.

\section{Acknowledgements}

We would like to thank Naresuan University, Thailand for financial support (research grant number R2560C115).

\section{References}

[1] CT Chao and RR Krueger. The date palm (Phoenix dactylifera L.): Overview of biology, uses, and cultivation. HortScience 2007; 42, 1077-82.

[2] W Al-shahib and RJ Marshall. The fruit of the date palm: Its possible use as the best food for the future? Int. J. Food Sci. Nutr. 2003; 54, 247-59.

[3] SM Al-Orf, MH Ahmed, N Al-Atwai, H Al-Zaidi, A Dehwah and S Dehwah. Nutritional properties and benefits of the date fruits (Phoenix dactylifera L.). Bull. Natl. Nutr. Inst. Arab Republic Egypt 2012; 39, 97-129.

[4] AME Sulieman, IAA Elhafise and AM Abdelrahim. Comparative study on five Sudanese date (Phoenix dactylifera L.) fruit cultivars. Food Nutr. Sci. 2012; 3, 1245-51.

[5] PK Vayalil. Antioxidant and antimutagenic properties of aqueous extract of date fruit (Phoenix dactylifera L. Arecaceae). J. Agr. Food Chem. 2002; 50, 610-7.

[6] F Biglari, AFM AlKarkhi and AM Easa. Antioxidant activity and phenolic content of various date palm (Phoenix dactylifera) fruits from Iran. Food Chem. 2008; 107, 1636-41.

[7] AR Tapas, DM Sakarkar and RB Kakde. Flavonoids as nutraceuticals: A review. Trop. J. Pharmaceut. Res. 2008; 7, 1089-99.

[8] N Intha and P Chaiprasart. Sex determination in date palm (Phoenix dactylifera L.) by PCR based marker analysis. Sci. Hortic. 2018; 236, 251-5.

[9] SA Bekheet and M Hanafy. Towards sex determination of date palm. In: SM Jain, JM Al-Khayri and DV Johnson (Eds.). Date palm biotechnology. Springer, Dordrecht, 2011, p. 551-66.

[10] PJ Ainsworth and V Buchanan-Wollaston. Sex determination in plants. Curr. Top. Dev. Biol. 1998; 38, 167-223.

[11] SM Jain. Date palm biotechnology: Current status and prospective-an overview. Emir. J. Food Agr. 2012; 24, 386-99.

[12] D Johnson. Introduction: date palm biotechnology from theory to practice. In: SM Jain, JM AlKhayri and DV Johnson (Eds.). Date Palm Biotechnology. Springer, Dordrecht, 2011, p. 1-11. 
[13] S Siljak-Yakovlev, M Cerbah, A Sarr, S Benmalek, N Bounaga, TCDL Pena and S Brown. Chromosomal sex determination and heterochromatin structure in date palm. Sex. Plant Reprod. 1996; 9, 127-32.

[14] RAA Younis, OM Ismail and SS Soliman. Identification of sex-specific DNA markers for date Palm (Phoenix dactylifera L.) using RAPD and ISSR techniques. Res. J. Agr. Biol. Sci. 2008; 4, 278-84.

[15] EK Al-Dous, B George, ME Al-Mahmoud, MY Al-Jaber, H Wang, YM Salameh, EK Al-Azwani, S Chaluvadi, AC Pontaroli, J DeBarry, V Arondel, J Ohlrogge, IJ Saie, KM Suliman-Elmeer, JL Bennetzen, RR Kruegger and JA Malek. De novo genome sequencing and comparative genomics of date palm (Phoenix dactylifera). Nat. Biotechnol. 2011; 29, 521-8.

[16] E Cherif, S Zehdi-Azouzi, A Crabos, K Castillo, N Chabrillange, JC Pintaud, A Salhi-Hannachi, S Glémin and F Aberlenc-Bertossi. Evolution of sex chromosomes prior to speciation in the dioecious Phoenix species. J. Evol. Biol. 2016; 29, 1513-22.

[17] S Kafkas, M Khodaeiaminjan, M Güney and E Kafkas. Identification of sex-linked SNP markers using RAD sequencing suggests ZW/ZZ sex determination in Pistacia vera L. BMC genom. 2015; 16, 98.

[18] K Sujipuli, S Urtgam, N Kunpratum and T Jongjitvimo. Development of Specific-Molecular Marker for sex determination among papaya cultivars grown in Phitsanulok province, Thailand. NU. Int. J. Sci. 2016; 13, 1-10.

[19] ME Al-Mahmoud, EK Al-Dous, EK Al-Azwani, and JA Malek. DNA-based assays to distinguish date palm (Arecaceae) gender. Am. J. Bot. 2012; 99, e7-e10.

[20] JG Williams, AR Kubelik, KJ Livak, JA Rafalski and SV Tingey. DNA polymorphisms amplified by arbitrary primers are useful as genetic markers. Nucleic Acids Res. 1990; 18, 6531-5.

[21] A Modi, K Suthar, P Thakkar, MC Mankad, S Kumari, S Narayanan, AS Singh and N Kumar. Evaluation of sex specific RAPD and SCAR markers linked to papaya (Carica papaya L.). Biocatal. Agr. Biotechnol. 2018; 16, 271-6.

[22] J Kumar, M Heikrujam, K Sharma and V Agrawal. SRAP and SSR marker-assisted genetic diversity, population structure analysis and sex identification in Jojoba (Simmondsia chinensis). Ind. Crop. Prod. 2019; 133, 118-32.

[23] Y Zhou, W Wu, Z Ning and R Zhou. Identification and characterization of sex-specific markers in the milky mangrove Excoecaria agallocha using double digest restriction site-associated DNA sequencing. Aquat. Bot. 2018; 144, 54-60.

[24] MED Solliman, HAA Mohasseb, AA Al-Khateeb, SA Al-Khateeb, K Chowdhury, HA El-Shemy and MI Aldaej. Identification and sequencing of Date-SRY Gene: A novel tool for sex determination of date palm (Phoenix dactylifera L.). Saudi J. Biol. Sci. 2019; 26, 514-23.

[25] PY Kwok. Methods for genotyping single nucleotide polymorphisms. Annu. Rev. Genomics Hum. Genet. 2001; 2, 235-258.

[26] N Urasaki, K Tarora, A Shudo, H Ueno, M Tamaki, N Miyagi, S Adaniya and H Matsumura. Digital transcriptome analysis of putative sex-determination genes in papaya (Carica papaya). PLoS One. 2012; 7, e40904.

[27] Y Hong, MK Pandey, Y Liu, X Chen, H Liu, RK Varshney, X Liang and S Huang. Identification and evaluation of single-nucleotide polymorphisms in allotetraploid peanut (Arachis hypogaea L.) based on amplicon sequencing combined with high resolution melting (HRM) analysis. Front. Plant Sci. 2015; 6, 1068.

[28] A Ribeiro, A Golicz, CA Hackett, I Milne, G Stephen, D Marshall, AJ Flavell and M Bayer. An investigation of causes of false positive single nucleotide polymorphisms using simulated reads from a small eukaryote genome. BMC Bioinformatics 2015; 16, 382.

[29] R Horn, A Radanovic, L Fuhrmann, Y Sprycha, S Hamrit, M Jockovic, D Miladinovic and C Jansen. Development and validation of markers for the fertility restorer gene Rf1 in Sunflower. Int. J. Mol. Sci. 2019; 20, 1260.

[30] T Koyama, A Ozaki, K Yoshida, J Suzuki, K Fuji, JY Aoki, W Kai, Y Kawabata, T Tsuzaki, K Araki and $\mathrm{T}$ Sakamoto. Identification of sex-linked SNPs and sex-determining regions in the yellowtail genome. Mar. Biotechnol. 2015; 17, 502-10. 